\title{
The Effects of Diseases of the Liver, Thyroid, and Kidneys on the Transport of Vitamin A in Human Plasma
}

\author{
Frank Rees Smith and DeWitt S. Goodman \\ From the Department of Medicine, Columbia University College of Physicians \\ and Surgeons, New York 10032
}

A в S T R A C T The effects of diseases of the liver, the thyroid, and the kidneys on the retinol-binding protein (RBP)-prealbumin (PA) system responsible for the transport of vitamin $\mathrm{A}$ in plasma were examined, using a radial gel diffusion immunoassay for $\mathrm{PA}$ and the previously described radioimmunoassay for RBP. Measurements were made on plasma samples from 118 normal subjects, 31 patients with cirrhosis, 5 with chronic active hepatitis, 27 with acute viral hepatitis, 14 patients with hyperthyroidism, 7 with hypothyroidism, and 26 patients with chronic renal disease of varying etiologies. In the patients with liver disease, the levels of vitamin $\mathrm{A}, \mathrm{RBP}$, and PA were all markedly decreased and were highly significantly correlated over a wide range of concentrations. Serial samples were available in 19 patients with acute hepatitis; as the disease improved the plasma concentrations of vitamin $\mathrm{A}, \mathrm{RBP}$, and $\mathrm{PA}$ all increased. In patients with acute hepatitis RBP concentrations correlated negatively with the levels of plasma bilirubin, glutamic-oxaloacetic transaminase, and alkaline phosphatase. In the hyperthyroid patients both RBP and PA concentrations were significantly lower than normal; in hypothyroidism, neither protein showed levels significantly different from normal. In both hyper- and hypothyroidism and in liver disease, the molar ratios of RBP : PA and of RBP : vitamin A were not significantly different from normal.

Patients with chronic renal disease had marked abnormalities in the plasma concentrations of RBP and vitamin $A$ and in the molar ratios examined. In renal disease the levels of both RBP and vitamin A were greatly elevated, while the PA levels remained normal. The molar ratios of RBP:PA and of RBP: vitamin A were both markedly elevated. In many patients RBP was present in molar excess as compared with PA. The pres-

Dr. Goodman is a Career Scientist of the Health Research Council of the City of New York under Contract I-399.

Received for publication 22 April 1971 and in revised form 23 June 1971. ence of a relatively large proportion of free $\mathrm{RBP}$, not complexed to $\mathrm{PA}$, in some patients with chronic renal disease was confirmed by gel filtration. The free RBP, present in molar excess, was capable of forming a complex with additional purified PA added to the plasma. The kidneys appear to play an important role in the normal metabolism of RBP.

\section{INTRODUCTION}

We have recently reported the development of a radioimmunoassay for human plasma retinol-binding protein $(R B P)^{1}(1)$. RBP, the specific transport protein for vitamin $\mathrm{A}$, has a molecular weight of approximately 21,000 and a single binding site for one molecule of retinol (2). In plasma, RBP circulates as a proteinprotein complex with plasma prealbumin (PA). The prealbumin which forms a complex with $\mathrm{RBP}$ is identical with the so-called thyroxine-binding prealbumin in human plasma. Studies with the analytical ultracentrifuge have demonstrated that purified $\mathrm{RBP}$ and PA associate to form a 1:1 molar complex. When RBP-PA mixtures containing either protein in amounts in excess of a 1:1 molar ratio were analyzed, the results showed the presence in these mixtures of a $1: 1$ molar RBP-PA complex together with the free uncomplexed protein present in excess of this molar ratio (3). The RBP-PA complex remained stable in the temperature range $4^{\circ}-$ $42.5^{\circ} \mathrm{C}$ and in the $\mathrm{pH}$ range $5.8-7.5$, but could be reversibly dissociated by the addition of $6 \mathrm{~m}$ urea (3).

The radioimmunoassay for RBP was previously used to examine the plasma levels of RBP in normal adults (1). The mean ( \pm SEM) levels observed were $47.2 \pm 1.6$ $\mu \mathrm{g} / \mathrm{ml}$ for males and $41.6 \pm 1.6 \mu \mathrm{g} / \mathrm{ml}$ for females. There was a highly significant correlation between the plasma levels of RBP and of vitamin A. Plasma RBP

\footnotetext{
${ }^{1}$ Abbreviations used in this paper: GOT, glutamic-oxaloacetic transaminase; $\mathrm{PA}$, prealbumin; $\mathrm{RBP}$, retinol-binding protein.
} 
was generally saturated with retinol, suggesting that under normal circumstances RBP circulates almost exclusively as the holoprotein. Data were also reported showing that plasma RBP levels were markedly decreased in a small group of patients with acute viral hepatitis.

We now report the results of more extensive studies in which the levels of all of the components of the vitamin A transport system (RBP, PA, and vitamin A) were determined in individual plasma samples. These studies were carried out in normal subjects and in patients with diseases of the liver (cirrhosis, acute and chronic hepatitis), diseases of the thyroid, or with chronic renal disease. The results demonstrate that diseases of each of these organs affect vitamin A transport in a different manner and provide new information about the normal and abnormal metabolism of plasma $\mathrm{RBP}$ in man.

\section{METHODS}

Purification of $R B P$ and $P A ; R B P$ immunoassay. Human plasma RBP and PA were isolated by a sequence of procedures described in detail in our previous publications (1-4). Rabbit anti-human RBP antisera and ${ }^{181}$ I-labeled RBP were prepared, and RBP was measured by the radioimmunoassay procedure as described in detail previously (1).

Radial gel diffusion assay for $P A .41 \mathrm{ml}$ of a mixture of agar, ${ }^{2} 1 \%$ by weight in $0.05 \mathrm{~m} \mathrm{Na}$ phosphate buffer $\mathrm{pH}$ 7.6, was heated to clarity in a water bath, cooled to $64^{\circ} \mathrm{C}$, and mixed with $1 \mathrm{ml}$ of anti-human PA antiserum made in rabbits. ${ }^{3}$ Immediately after mixing, 4-ml portions were applied to $2 \times 6 \mathrm{~cm}$ glass slides and allowed to harden at room temperature for $2 \mathrm{hr}$. Lyophilized PA was dissolved in water or in $0.9 \% \mathrm{NaCl}$ and diluted serially to final concentrations of $90-10 \mu \mathrm{g} / \mathrm{ml}$. The concentrations of the PA solutions were calculated by determining the absorbance of the initial solution at $280 \mathrm{~nm}$, assuming an $E_{1 \% \mathrm{~m}}^{1 \%}$ of 14.1 (4). Human plasma was diluted $1: 5$ or $1: 10(\mathrm{v} / \mathrm{v})$ with water or $0.9 \% \mathrm{NaCl}$. Wells $2.5 \mathrm{~mm}$ in diameter were made in the gels with a cork borer, and the wells were filled with one or another standard PA solution or with samples of diluted plasma. In general, each slide contained some standards and some diluted plasma samples. All samples were analyzed in duplicate; duplicate samples were, moreover, applied to different slides. The gels were placed over water in a closed polystyrene box, allowed to remain undisturbed for 18-36 hr, and the diameter of the precipitin ring was measured with calipers and a magnifying lens without knowledge of the identity of the samples. The standard curve was found to be linear in the concentration range studied when the logarithm of $\mathrm{PA}$ concentration was plotted against the diameter of the precipitin ring (Fig. 1). A standard curve was determined in each set of assays and was used to calculate the concentrations of $\mathrm{PA}$ in that particular set of samples.

Recovery of $P A$. Normal plasma with a known concentration of PA was diluted with water to a PA concentration of $34 \mu \mathrm{g} / \mathrm{ml}$, and portions of the diluted plasma were

'Special Agar-Noble, Difco Laboratories, Detroit, Mich.

${ }^{3}$ American Hoechst Corporation, Somerville, N. J.

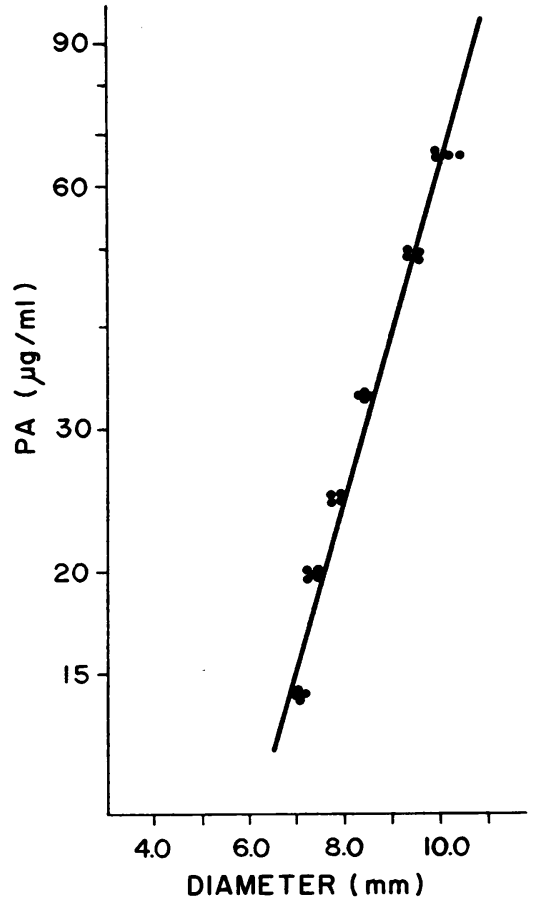

FIGURE 1 Standard curve for the radial gel diffusion immunoassay for plasma prealbumin.

mixed with an equal volume of one of six solutions of pure PA containing PA in concentrations ranging from 6 to $38 \mu \mathrm{g} / \mathrm{ml}$. Six determinations were made with each mixture, and the observed values were compared with those calculated from the known concentrations of the mixtures. The mean recovery of the pure PA added to diluted plasma was $95 \%$.

Intra-assay (within assay) agreement. Plasma samples were assayed in duplicate for $\mathrm{PA}$, and the mean was taken as the final value. During an 8 month period the values for duplicate assays on 100 successive plasma samples differed from the mean of each duplicate pair by a mean ( \pm SD) of $6.4 \pm 7.4 \%$. In the studies reported here the results for a given sample were discarded when the duplicates differed by more than $20 \%$ and that assay was repeated.

Interassay (between assay) agreement. During the same 8 month period 50 plasma samples were analyzed for PA in duplicate in more than one assay. The mean values $( \pm \mathrm{SD})$ between assays for these samples varied by 9.0 $\pm 5.8 \%$ from the over-all mean for each sample.

Radial gel diffusion assay for serum albumin. A mixture of agar, $1 \%$ by weight in $0.02 \mathrm{M} \mathrm{Na}$ phosphate buffer $\mathrm{pH}$ $7.6,42 \mathrm{ml}$ in volume, was mixed with $2 \mathrm{ml}$ of anti-human serum albumin antiserum, ${ }^{3}$ and gels were prepared as described above. Human serum albumin ${ }^{3}$ was dissolved in $0.9 \% \mathrm{NaCl}$, the concentration was determined from the absorbance at $280 \mathrm{~nm}$ assuming an $E_{1 \mathrm{~cm}}^{1 \%}$ of $5.8,{ }^{3}$ and the solution was diluted serially to final concentrations of 900 $100 \mu \mathrm{g} / \mathrm{ml}$. Human plasma was diluted $1: 75(\mathrm{v} / \mathrm{v})$ with $0.9 \% \mathrm{NaCl}$, and samples and standard solutions were assayed in duplicate in a manner similar to the gel diffusion assay for PA.

Plasma samples. $10-15 \mathrm{ml}$ of venous blood was drawn 
TABLE I

Characteristics of the Subjects and Patients Studied

\begin{tabular}{lrrrrr}
\hline & \multicolumn{2}{c}{ No. of subjects } & & \multicolumn{2}{c}{ Age } \\
\cline { 2 - 2 } \cline { 5 - 6 } \multicolumn{1}{c}{ Diagnosis } & Males & Females & & Mean & Range \\
\hline & & & & \multicolumn{2}{c}{$y r$} \\
Normal & 61 & 57 & & 32 & $17-73$ \\
Cirrhosis & 11 & 20 & & 55 & $26-72$ \\
Chronic active hepatitis & 3 & 2 & & 35 & $21-66$ \\
Acute viral hepatitis & 15 & 12 & & 23 & $15-55$ \\
Hyperthyroidism & 1 & 13 & & 45 & $19-85$ \\
Hypothyroidism & 1 & 6 & & 58 & $48-66$ \\
Chronic renal disease & 13 & 13 & & 40 & $17-67$ \\
\hline
\end{tabular}

into heparinized vacutainer ${ }^{4}$ tubes, and the plasma was separated by centrifugation for $30 \mathrm{~min}$ at $2000 \mathrm{rpm}$ at $4^{\circ} \mathrm{C}$. Portions were sent to the clinical laboratory for determinations described below, and the remainder was stored in the dark at $-20^{\circ} \mathrm{C}$ until assayed.

Clinical characteristics of the subjects studied. The normal subjects were hospital employees who were having venous blood drawn as part of a routine medical examination. None of the female subjects was taking oral contraceptives. The patients were attending medical clinics at the Columbia Presbyterian Medical Center or were hospitalized on the medical service at the Presbyterian Hospital or the Francis Delafield Hospital. The sex and age distribution of the normal subjects and the patients is shown in Table I. Of the 31 patients with cirrhosis a tissue diagnosis was available in 22.24 patients were diagnosed as having Laennec's cirrhosis, 6 had postnecrotic cirrhosis, and 1 had biliary cirrhosis. 14 patients with cirrhosis had undergone portacaval or splenorenal bypass surgical procedures. A tissue diagnosis was available in all 5 patients with chronic active hepatitis. 27 patients with acute viral hepatitis were studied; serial samples were obtained at different times during the course of the hepatitis in 19 of these patients. Values from the initial plasma samples, which were usually collected within 2 wk of the onset of symptoms, were grouped as "early hepatitis." The clinical laboratory values obtained from these samples were (mean $\pm \mathrm{SEM}$ ): bilirubin $8.4 \pm 1.5 \mathrm{mg} / 100 \mathrm{ml}$ (normal 0.5-1.0); glutamic-oxaloacetic transaminase (GOT) $899 \pm 204$ (normal 10-50) milliinternational units per milliliter $(\mathrm{mU} / \mathrm{ml})$; and alkaline phosphatase $145 \pm 15$ (normal $30-85$ ) $\mathrm{mU} / \mathrm{ml}$ Values from the final plasma samples, obtained when the patients were symptom-free and the liver function tests were nearly normal, were grouped as "late hepatitis." The plasma concentrations in these samples were (mean \pm SEM) : bilirubin $1.4 \pm 0.2 \mathrm{mg} / 100 \mathrm{ml}$; GOT $83 \pm 21 \mathrm{mU} / \mathrm{ml}$; alkaline phosphatase $73 \pm 11 \mathrm{mU} / \mathrm{ml}$. "Late" samples were not available on three patients who were studied with serial samples (two patients completed their convalescence elsewhere and one died with acute yellow atrophy). 12 of 18 patients with hepatitis, who were tested for Australia antigen, were positive. The mean \pm SEM number of samples assayed per patient with acute viral hepatitis was $3.3 \pm 0.3$ with a range from 1 to 8 . The values for all other patients represent determinations from single samples except for those with renal disease undergoing hemodialysis where pre- and postdialyses values were averaged.

\footnotetext{
'Becton-Dickinson \& Co., Rutherford, N. J.
}

Information about the 26 patients with chronic renal disease is given in Table II.

The plasma thyroxine iodine level was $12.1 \pm 1.0 \mu \mathrm{g} / 100$ $\mathrm{ml}$ (mean \pm SEM) in the 14 patients with hyperthyroidism and was $1.3 \pm 0.3$ in the 7 patients with hypothyroidism (normal level 3.2-6.4 $\mu \mathrm{g} / 100 \mathrm{ml}$ ). The patients with thyroid disease were not studied after therapy.

Laboratory tests. On Presbyterian Hospital patients, plasma urea nitrogen, albumin, total bilirubin, alkaline phosphatase, and GOT levels were determined on a 12channel AutoAnalyzer (Technicon ${ }^{5}$ SMA 12/60). Plasma albumin levels in normal subjects were determined by radial gel immunodiffusion as described above. In patients receiving hemodialysis treatment at Delafield Hospital, serum nonprotein nitrogen values were determined by nesslerization (5), and the urea level was calculated by subtracting $25 \mathrm{mg} / 100 \mathrm{ml} \mathrm{(6)}$. Thyroxine iodine levels were measured by the column chromatographic method of Pileggi, Lee, Golub, and Henry (7).

Vitamin $A$ determinations. Plasma vitamin A levels were measured by the trifluoroacetic acid method of Dugan, Frigerio, and Siebert (8) as modified by Roels and Mahadevan (9), or by the fluorometric method of Thompson, ${ }^{6}$ Erdody, Brien, and Murray (10).

Statistics. Linear regression lines were calculated by the method of least squares; regression lines, correlation coefficients, and mean values were calculated on an Olivetti ${ }^{7}$ Programma 101 using programs prepared for that instrument (11). Significance was assessed as outlined by Snedecor and Cochran (12) and by Mainland (13).

Demonstration of free (uncomplexed) RBP in plasma in patients with renal failure. 1- to 2-ml portions of fresh or thawed plasma were applied directly to a column, $1.7 \times$ $70 \mathrm{~cm}$ ( $160 \mathrm{ml}$ bed volume) of Sephadex G-100 equilibrated with $0.02 \mathrm{M} \mathrm{Na}$ phosphate buffer $\mathrm{pH} 7.4,0.2 \mathrm{M} \mathrm{NaCl}$. The proteins were eluted with the same buffer at a flow rate of $15 \mathrm{ml} / \mathrm{hr}$ at $4^{\circ} \mathrm{C}$ in the dark. The absorbance of the eluted fractions ( $6 \mathrm{ml}$ volume each) was measured at 280 $\mathrm{nm}$ with a Beckman DB spectrophotometer, and the fluorescence of retinol bound to RBP (excitation $333 \mathrm{~nm}$, emission $460 \mathrm{~nm}$ ) in the fractions was measured with an Aminco-Bowman spectrophotofluorometer. ${ }^{8}$ In the experiments where fractions were pooled before assay for RBP and vitamin $\mathrm{A}$, the peaks corresponding to the RBP-PA complex and to free (uncomplexed) RBP were identified by the characteristic vitamin A fluorescence (3).

In one experiment, plasma obtained from a patient with renal failure was enriched with PA before gel filtration. In this experiment, lyophilized pure PA, $1 \mathrm{mg}$, was dissolved in $1 \mathrm{ml}$ of plasma and the PA-enriched plasma then chromatographed on Sephadex G-100 as described.

Molar ratios. In calculating the molar ratios the molecular weight of RBP was assumed to be 21,000 and of PA $49,400(3)$.

\section{RESULTS}

$P A$ levels in normal adults. The mean \pm SEM level of plasma PA was $263 \pm 7 \mu \mathrm{g} / \mathrm{ml}$ for males and $238 \pm 6$ $\mu \mathrm{g} / \mathrm{ml}$ for females. The mean level of PA was significantly higher $(t=2.71, P<0.01)$ in males than in

s Technicon Co., Inc., Tarrytown, N. Y.

${ }^{6}$ Thompson, J. N. Personal communication.

${ }^{7}$ Olivetti Underwood Corp., New York.

${ }^{8}$ American Instrument Co., Inc., Silver Spring, Md. 


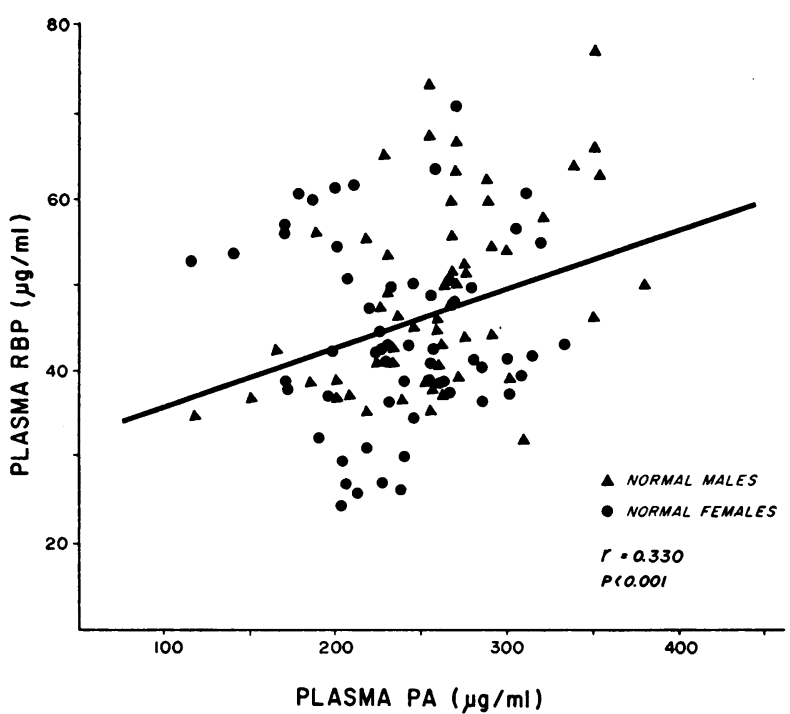

FIGURE 2 Correlation between plasma PA and RBP levels in normal subjects. The regression line is drawn for the entire group, including both males and females.

females. In the normal adults studied, no correlation was found between plasma PA levels and age. Plasma PA and RBP levels were significantly correlated $(r=0.430$, $P<0.001)$ in males but not in females. The correlation of plasma PA and RBP levels in the entire group of normal males and females $(r=0.330, P<0.001)$ is shown in Fig. 2. Plasma PA levels were correlated significantly $(r=0.364, P<0.001)$ with plasma vitamin A levels, a result anticipated in view of the previously observed (1) correlation between RBP and vitamin A levels. Plasma albumin levels, in contrast, were not correlated with RBP levels.

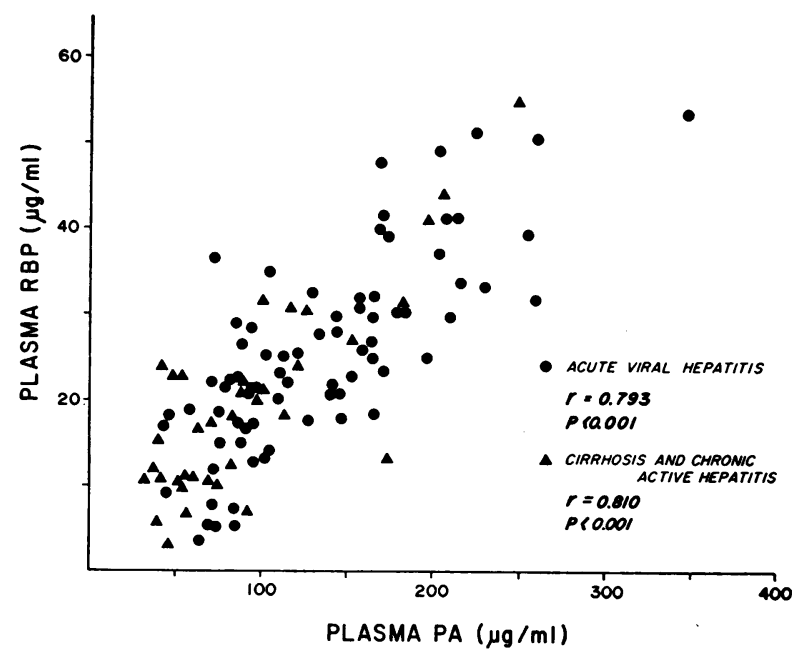

Figure 3 Correlation between plasma PA and RBP levels in patients with acute viral hepatitis, chronic active hepatitis, and cirrhosis.

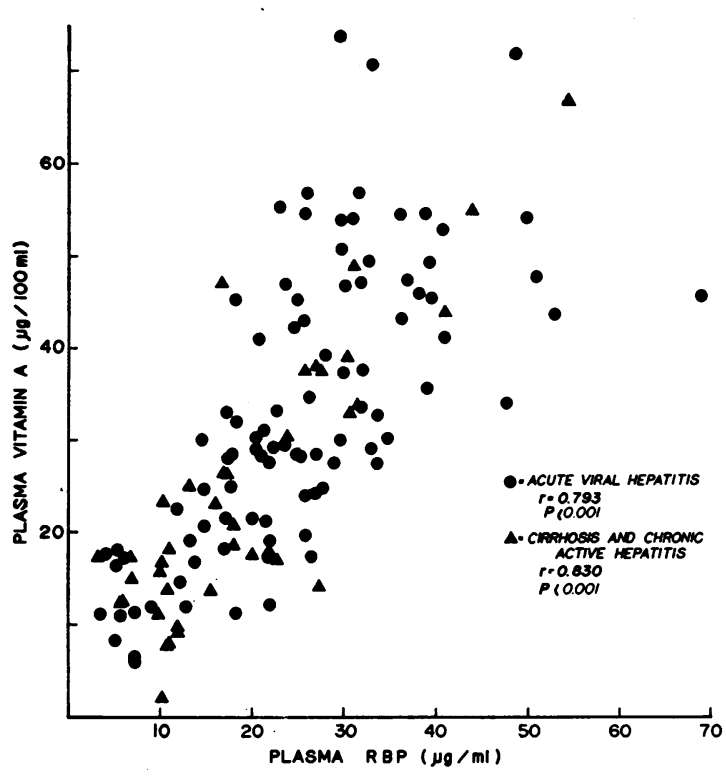

FIGURE 4 Correlation between plasma RBP and vitamin A levels in patients with acute viral hepatitis, chronic active hepatitis, and cirrhosis.

Effects of liver disease on the vitamin $A$ transport system. Plasma RBP and PA levels in patients with acute viral hepatitis, chronic active hepatitis, and cirrhosis are shown in Fig. 3. The levels of the two proteins were highly significantly correlated over the wide range of concentrations found in patients with liver disease. In Fig. 4, a similar highly significant correlation is shown between plasma RBP and vitamin A levels in the same patients. In patients with acute viral hepatitis, where serial plasma samples were available as the disease

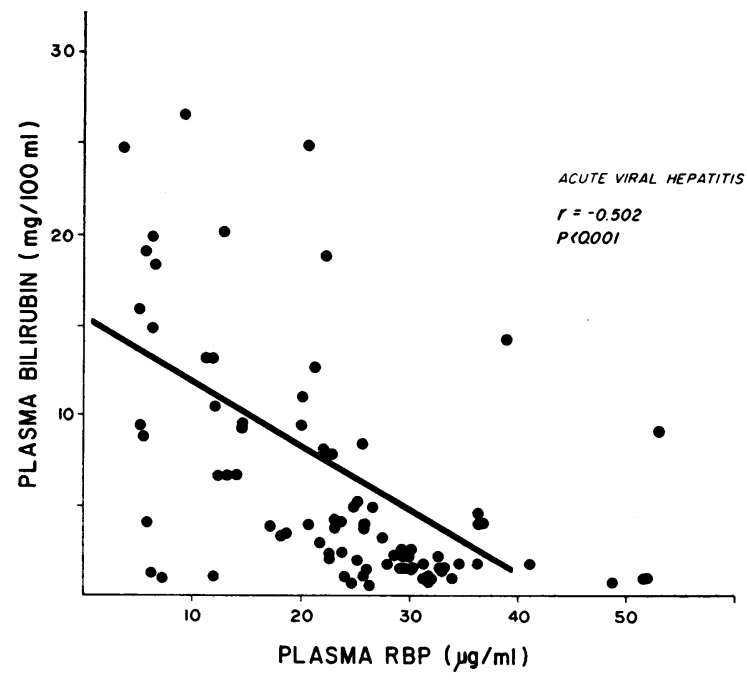

FIGURE 5 Correlation (negative) between plasma RBP and bilirubin levels in serial samples from patients with acute viral hepatitis. 


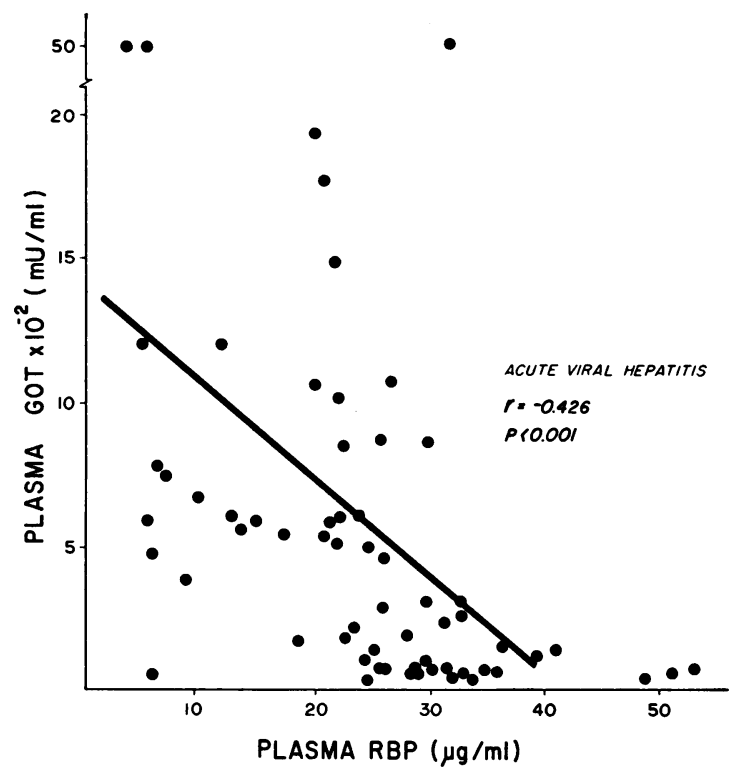

FIgURE 6 Correlation (negative) between plasma RBP and glutamic-oxaloacetic transaminase levels in serial samples from patients with acute viral hepatitis.

improved, it was possible to compare RBP levels with the standard tests of liver function during the course of the disease. A significant negative correlation was observed between plasma RBP and bilirubin levels (Fig. 5) and between plasma RBP and GOT levels (Fig. 6). Plasma RBP levels showed a negative correlation ( $r$ $=-0.370, P<0.01)$ as well with the levels of alkaline phosphatase activity. The highly significant depressions in mean ( \pm SEM) plasma RBP levels in patients with cirrhosis, chronic active hepatitis, and acute viral hep- atitis compared with normal subjects are shown in Table III. Plasma PA concentrations were similarly depressed in these groups of patients with liver disease, as were the levels of vitamin A (see Table III). Despite these marked reductions in the levels of RBP, PA, and vitamin $A$, the molar ratios in plasma $R B P: P A$ and of $\mathrm{RBP}$ : vitamin A were not significantly different in patients with liver disease from the ratios seen in normal subjects (Table IV).

Effects of thyroid disease on the vitamin A transport system. In the 14 patients with hyperthyroidism, the mean levels of both plasma RBP and PA were significantly lower than the mean levels seen in the normal subjects (see Table III). Since 13 of the 14 hyperthyroid patients were females, and since both plasma PA and RBP (see reference 1) levels are lower in normal females than males, calculations were also carried out to compare the RBP, PA, and vitamin A levels in the hyperthyroid females with the corresponding values in normal females. These calculations indicated that, as with the entire group, both plasma $\operatorname{RBP}(P<0.01)$ and PA $(P<0.001)$ levels were significantly lower than normal in hyperthyroid females. The levels of plasma vitamin A were generally lower in hyperthyroid than in normal subjects, but this difference was not statistically significant.

The hypothyroid patients were also compared with normal subjects both by comparing the entire group of patients with the entire group of normals and by comparing hypothyroid with normal females. Similar findings were obtained in both sets of comparisons. In hypothyroidism the plasma level of vitamin A was significantly $(P<0.05)$ increased to $69 \pm 9.4 \mu \mathrm{g} / 100 \mathrm{ml}$;

TABLE II

Characteristics of Patients with Chronic Renal Disease

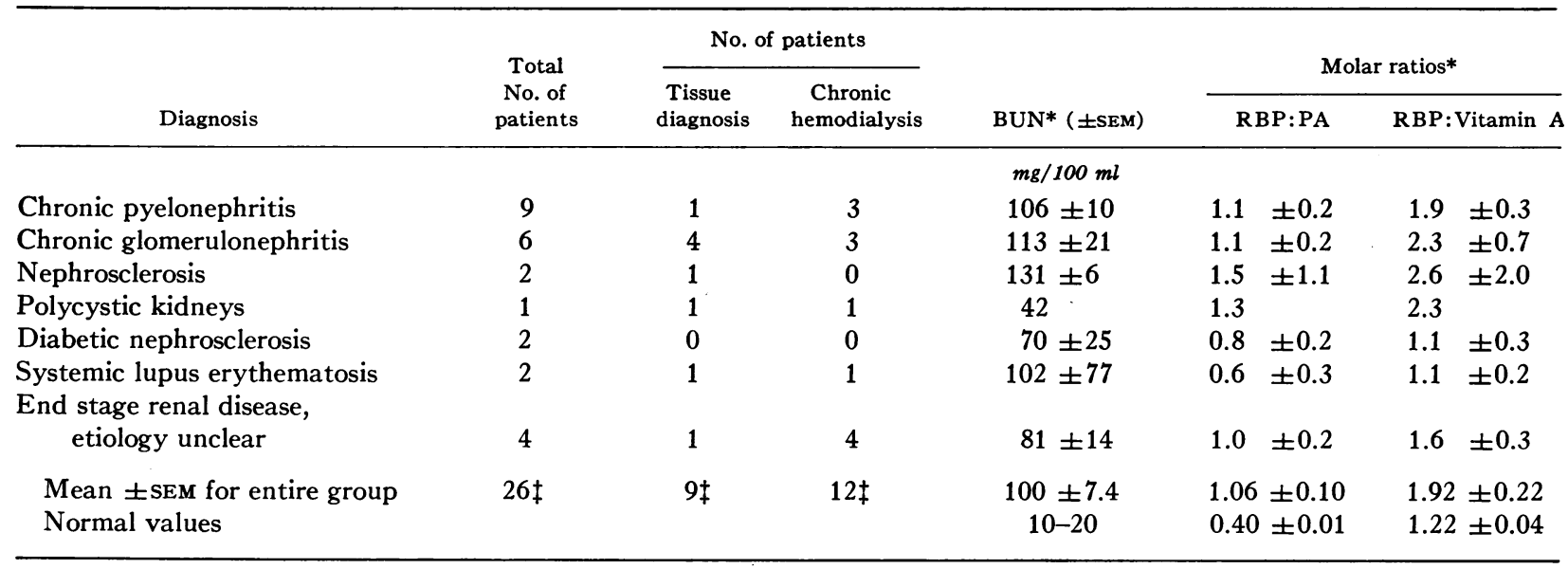

* Mean 土SEM.

$\ddagger$ Total No. of patients. 
TABLE III

Plasma Concentrations of RBP, PA, and Vitamin A in Normal Subjects and in Patients with Liver, Thyroid, and Renal Disease

\begin{tabular}{|c|c|c|c|c|c|c|c|}
\hline \multirow[b]{2}{*}{ Diagnosis } & \multirow[b]{2}{*}{$\mathrm{n}^{*}$} & \multicolumn{2}{|c|}{ RBP } & \multicolumn{2}{|c|}{ PA } & \multicolumn{2}{|c|}{ Vitamin A } \\
\hline & & $\mu \mathrm{g} / \mathrm{ml}$ & $P \S$ & $\mu \mathrm{g} / \mathrm{mlf}$ & $P \S$ & $\mu \mathrm{g} / 100 \mathrm{mlt}$ & $P \S$ \\
\hline Normal & 109 & $46.2 \pm 1.0$ & & $250 \pm 5$ & & $50.1 \pm 1.5$ & \\
\hline Cirrhosis & 31 & $19.3 \pm 2.1$ & $<0.001$ & $94 \pm 10$ & $<0.001$ & $25.0 \pm 2.7$ & $<0.001$ \\
\hline Chronic active hepatitis & 5 & $21.2 \pm 4.6$ & $<0.001$ & $92 \pm 22$ & $<0.001$ & $24.4 \pm 4.7$ & $<0.001$ \\
\hline Acute viral hepatitis "early" & 19 & $18.5 \pm 1.7$ & $<0.001$ & $102 \pm 6$ & $<0.001$ & $25.0 \pm 2.3$ & $<0.001$ \\
\hline Acute viral hepatitis "late" & 16 & $36.3 \pm 2.6$ & $<0.001$ & $194 \pm 16$ & $<0.001$ & $40.6 \pm 3.2$ & $<0.01$ \\
\hline Hyperthyroidism & 14 & $31.2 \pm 3.1$ & $<0.001$ & $148 \pm 14$ & $<0.001$ & $41.2 \pm 5.0$ & NS \\
\hline Hypothyroidism & 7 & $57.0 \pm 7.1$ & NS & $245 \pm 29$ & NS & $67.7 \pm 9.4$ & $<0.05$ \\
\hline Chronic renal disease & 26 & $116 \pm 9.3$ & $<0.001$ & $268 \pm 20$ & NS & $98.2 \pm 9.0$ & $<0.001$ \\
\hline
\end{tabular}

$* \mathrm{n}=$ No. of subjects.

$\ddagger$ All values listed are mean \pm SEM.

$\S P=$ probability that mean value does not differ from normal mean value. NS = not significantly different from normal $(P>0.05)$.

the mean level of RBP was somewhat higher than normal in these subjects, but the difference was not statistically significant (Table III). The levels of plasma PA in the hypothyroid patients were similar to the levels seen in normal subjects. The molar ratios of RBP:PA and of RBP:vitamin A were not significantly different from normal in either the hyperthyroid or in the hypothyroid patients (Table IV).

Effects of severe renal disease. In the group of 26 patients with renal disease of varying etiologies (see Table II), both the mean levels of plasma RBP (116 $\mu \mathrm{g} / \mathrm{ml})$ and of vitamin A $(98 \mu \mathrm{g} / 100 \mathrm{ml})$ were markedly elevated, while the PA levels remained normal (Table
III). The mean ( \pm SEM $)$ molar ratio of plasma RBP :PA $(1.06 \pm 0.10)$ was much higher than the normal mean value $(0.40 \pm 0.01)$, and 8 of the 26 patients had $\mathrm{RBP}$ : PA molar ratios of 1.3 or higher (range 1.3-2.3 in these 8 patients). The molar ratio of plasma RBP :vitamin A was also significantly, although less markedly, increased as compared with the normal value (see Table II). These striking abnormalities in the plasma RBP and vitamin A levels, and in the molar ratios, were found in patients in the various diagnostic categories (Table II) and also in patients with and without maintenance hemodialysis.

Demonstration of free (uncomplexed) RBP in plasma

TABLE IV

Molar Ratios of RBP:PA and of RBP:Vitamin A in Normal Subjects and in Patients with Liver, Thyroid, and Renal Disease

\begin{tabular}{|c|c|c|c|c|c|}
\hline \multirow[b]{2}{*}{ Diagnosis } & \multirow[b]{2}{*}{$\mathrm{n}^{*}$} & \multicolumn{2}{|c|}{ RBP:PA } & \multicolumn{2}{|c|}{ RBP:Vitamin A } \\
\hline & & Mean \pm SEM & Range & Mean \pm SEM & Range \\
\hline Normal & 109 & $0.40 \pm 0.01$ & $0.23-0.77$ & $1.22 \pm 0.04$ & $0.62-2.53$ \\
\hline Cirrhosis & 31 & $0.39 \pm 0.04$ & $0.14-1.07$ & $1.16 \pm 0.11$ & $0.24-2.99$ \\
\hline Chronic active hepatitis & 5 & $0.49 \pm 0.07$ & $0.33-1.02$ & $1.25 \pm 0.23$ & $0.60-2.10$ \\
\hline Acute viral hepatitis "early" & 19 & $0.32 \pm 0.05$ & $0.17-0.76$ & $1.00 \pm 0.11$ & $0.41-2.47$ \\
\hline Acute viral hepatitis "late" & 16 & $0.41 \pm 0.02$ & $0.32-0.77$ & $1.24 \pm 0.08$ & $0.92-1.90$ \\
\hline Hyperthyroidism & 14 & $0.42 \pm 0.06$ & $0.21-1.03$ & $1.16 \pm 0.11$ & $0.60-1.92$ \\
\hline Hypothyroidism & 7 & $0.49 \pm 0.06$ & $0.33-0.67$ & $1.15 \pm 0.08$ & $0.90-1.53$ \\
\hline Chronic renal disease & 26 & $1.06 \pm 0.10 \ddagger$ & $0.37-2.30$ & $1.92 \pm 0.22 \S$ & $0.54-5.20$ \\
\hline
\end{tabular}

$*^{*} \mathrm{n}=$ No. of subjects.

$\ddagger P<0.001$ compared with normal.

$\S P<0.003$ compared with normal. 

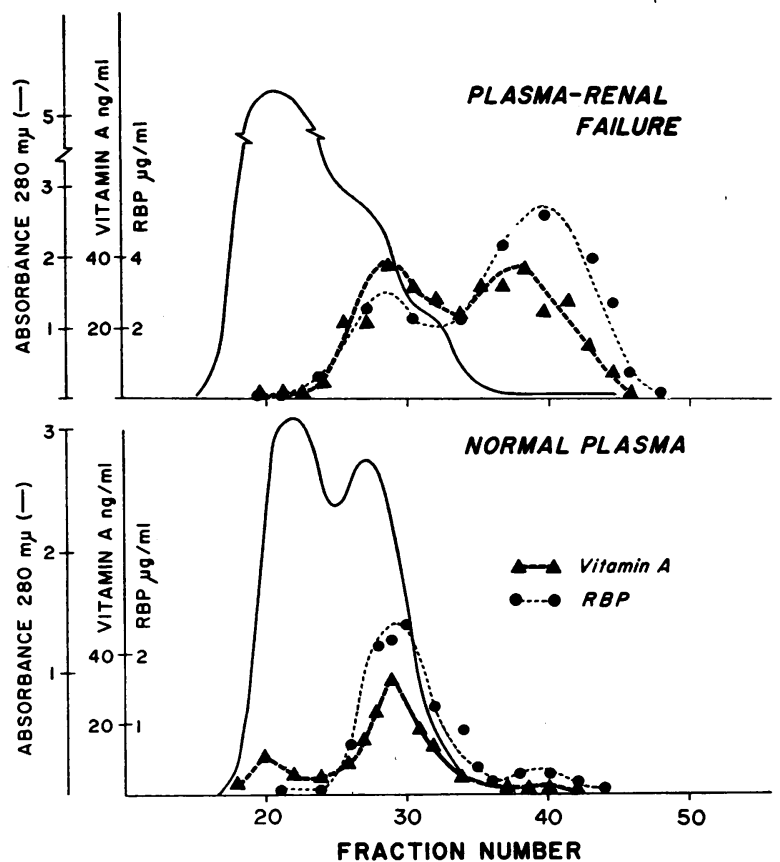

FIGURE 7 Demonstration of the presence of free RBP in plasma of a patient with renal disease. $2 \mathrm{ml}$ of plasma freshly drawn from patient $H$. C. was subjected to gel filtration on Sephadex G-100 as described in the Methods section. The eluted fractions were assayed for absorbance at $280 \mathrm{~nm}$ (as a measure of protein), and for RBP and vitamin $\mathrm{A}$; the results are shown in the top panel. A $2 \mathrm{ml}$ sample of plasma from a normal subject was chromatographed on the same column with the results shown in the bottom panel. Note that the units on the RBP scale in the top panel are twice those on the bottom.

from patients with renal failure. The finding that many of the patients with chronic renal disease had plasma RBP :PA molar ratios greater than one indicated that in these patients RBP was present in plasma in molar excess as compared with PA and that some of the RBP must therefore have been present not complexed with PA. In order to demonstrate this directly, plasma from a patient with chronic pyelonephritis being treated with chronic hemodialysis (BUN 99, molar ratios RBP:PA 1.5 and RBP : vitamin A 1.5) was subjected to gel filtration. When normal plasma was chromatographed on a column of Sephadex G-100 (Fig. 7, bottom panel), almost all of the RBP and vitamin $A$ were eluted together in a volume characteristic of the RBP-PA complex (peak at fractions 28-30, Fig. 7). When plasma from the patient with renal failure was chromatographed on the same Sephadex column, RBP and vitamin A were eluted in part with the same elution volume and in part in a volume characteristic of free, uncomplexed RBP (fractions 38-40 in Fig. 7, top panel). This experiment demonstrates the presence of a considerable amount of free (uncomplexed) $\mathrm{RBP}$ in the plasma of the patient with renal disease. In fact, the amount of RBP found in the second (free RBP) peak exceeded that expected from the measured molar ratio, if only the RBP present in molar excess as compared with PA had been present in free form. These observations suggest that the affinity of RBP for PA may have been decreased in this sample. Similar results were obtained with plasma from a second patient with severe nephrosclerosis (BUN 126, molar ratios of $R B P: P A \quad 2.3, R B P$ : vitamin $A$ 4.1). In addition, in both these plasma samples the ratio of $R B P$ to vitamin $A$ was higher in the second (free $R B P$ ) peak than in the first (RBP-PA complex) peak (see Fig. 7, top panel). This finding suggests that apo-RBP had a lesser affinity for PA than did holo-RBP, a conclusion consistent with our previous observations (3).

An experiment was conducted to determine whether the free RBP present in patients with renal disease was capable of forming a complex with PA. The possibility existed, for example, that much of the free RBP represented altered RBP molecules no longer capable of binding to PA. In order to examine this possibility, purified human PA was added to plasma from a patient with renal disease in an amount sufficient to restore the RBP : PA molar ratio to normal. Gel filtration of the plasma before the addition of PA showed that $70 \%$ of the total plasma RBP was eluted in a volume characteristic of free RBP (Fig. 8, middle panel). After the addition of $\mathrm{PA}$, however, both the $\mathrm{RBP}$ and vitamin $\mathrm{A}$ in the plasma sample were eluted almost entirely as the RBP-PA complex (Fig. 8, bottom panel). This finding indicates that the free RBP in this patient was structurally intact at least with regard to its ability to complex wih PA.

$R B P$ immunoassay of plasma from patients with hepatitis and renal failure. Serial dilutions of representative plasma samples with low RBP (hepatitis) and elevated RBP (renal failure) in the radioimmunoassay produced a displacement curve identical with that produced by standard pure RBP.

\section{DISCUSSION}

These studies were undertaken to examine the effects of diseases of the liver, the thyroid, and the kidneys on the RBP-PA system responsible for the transport of vitamin A in plasma. A radial gel diffusion immunoassay for PA was employed along with the previously reported radioimmunoassay for RBP (1), in order to measure the levels of both RBP and PA (as well as that of vitamin A) in individual samples of plasma. The results provide a detailed description of the effects of each of these diseases on the plasma vitamin A transport system and also provide insight into the normal and abnormal metabolism of $\mathrm{RBP}$ and vitamin $\mathrm{A}$ in man. 
Plasma concentrations in liver disease were of interest because of the indirect evidence that RBP is synthesized and secreted by the liver. It is well established that vitamin $A$ is mainly stored in, and can be mobilized readily from, the liver (14). We previously reported diminished plasma RBP levels in a small series of patients with acute viral hepatitis (1). In the present report, a more extensive study of RBP, PA, and vitamin A levels was conducted in a much larger series of patients, in an attempt to characterize fully the effects of liver disease on the vitamin A transport system and to correlate these effects with the standard laboratory tests of hepatic function.

More than two decades ago a number of reports appeared dealing with vitamin A metabolism in patients with liver disease. These reports demonstrated that plasma vitamin A levels were markedly decreased in patients with liver disease $(15,16)$. It was also found that dark adaptation was abnormal in patients with cirrhosis and that the administration of vitamin $\mathrm{A}$ was followed by some improvement (17). Tissue analyses in patients with liver disease demonstrated that the diseased liver generally had a lower than normal vitamin A content, but that the vitamin A content was often within the normal range $(15,18)$. Moreover, when the vitamin $A$ content of the liver was depressed it was much less abnormal than was the corresponding plasma level. It was suggested that the low plasma vitamin A level in hepatic diseases might be due in part to disturbed release of vitamin A from the liver (15, 19).

In the present studies of plasma from patients with cirrhosis, chronic active hepatitis, and acute viral hepatitis, the levels of vitamin A, RBP, and PA were all markedly decreased and were highly significantly correlated over a wide range of concentrations. In the patients with acute hepatitis, the RBP levels in plasma were correlated negatively with the values of three laboratory tests of hepatic function (bilirubin, GOT, and alkaline phosphatase concentrations). As the acute hepatitis improved, the plasma levels of vitamin A, RBP, and PA all increased. Despite the depressed plasma levels of these components, the molar ratios of $\mathrm{RBP}: \mathrm{PA}$ and RBP:vitamin A were not abnormal. These findings suggest that both RBP and PA are synthesized in and secreted by the liver and that their production rates are comparably disturbed in the presence of liver disease. The levels of RBP and PA in these patients appeared to be a valid index of the functional status of the liver. It is apparent that the decreased plasma vitamin A levels previously found in liver disease reflected the impaired hepatic synthesis and/or release of the transport proteins for vitamin A.

Previous studies of human plasma prealbumin have largely focused on the role of prealbumin as one of the

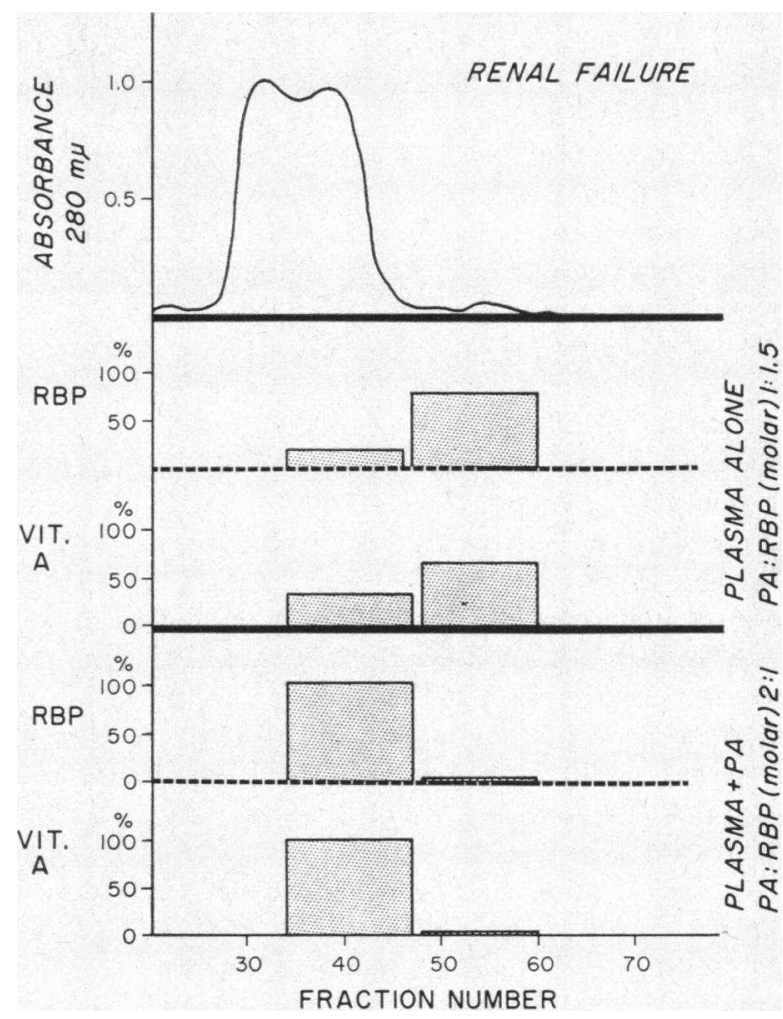

Figure 8 Effect of addition of $\mathrm{PA}$ to plasma from a patient with renal disease. A sample of plasma from patient $H$. C., which had been stored frozen for several weeks was thawed. $1 \mathrm{ml}$ of the plasma was chromatographed directly on Sephadex G-100 (see Methods section). PA (1 mg) was added to a second $1 \mathrm{ml}$ sample, and this was chromatographed 1 day later on the same column. The fractions ( $4 \mathrm{ml}$ each) were monitored for vitamin $A$ by fluorescence. Those fractions comprising the RBP-PA complex (fractions 34-47) were combined into a single pool, as were those fractions representing free uncomplexed RBP (fractions 48-60). The pools were assayed for RBP and vitamin A. The top panel in this figure shows the elution pattern for protein (absorbance at $280 \mathrm{~nm}$ ). The middle panel shows the distribution of $R B P$ and vitamin $A$ between the two pools for the plasma alone. The bottom panel shows similar results for plasma enriched with PA.

three proteins responsible for the plasma transport of thyroxine (20-22). The PA molecule appears to contain one binding site for one molecule of thyroxine (4, 23 ). Although the precise role of PA in thyroxine metabolism has as yet not been defined, recent papers suggest that under physiologic circumstances only of the order of $15 \%$ of plasma thyroxine circulates bound to PA $(24,25)$. The molar level of thyroxine in plasma is much less than that of PA; under normal circumstances less than $1 \%$ of the plasma PA molecules circulate in the form of a complex with thyroxine $(4,24)$. In contrast, as reported here, normally an average of 
$40 \%$ of the PA molecules circulate in the form of a complex with RBP.

The levels of plasma PA in normal subjects and in patients with thyroidal and nonthyroidal illnesses have been measured by several investigators. The majority of reported studies have utilized an indirect measure of PA concentration, the maximal binding capacity of PA for ${ }^{131}$ I-labeled thyroxine (26-30). Plasma PA concentration was also measured by densitometry after starch gel electrophoresis of a sample of plasma to which had been added varying concentrations of pure $\mathrm{PA}$, then extrapolating to the endogenous concentration (23). Plasma PA levels have been measured directly by densitometry after polyacrylamide (31) or starch gel (32) electrophoresis and after radial diffusion on cellulose acetate strips sprayed with dilute antisera $(33,34)$. The normal mean ( $($ SEM) level of plasma PA of $250 \pm 5 \mu \mathrm{g} / \mathrm{ml}$, as determined by us by radial immunodiffusion in agar gel, compares closely with previously reported normal mean values of $277 \mu \mathrm{g} / \mathrm{ml}(29), 266 \mu \mathrm{g} / \mathrm{ml}$ (34), and 250 $\mu \mathrm{g} / \mathrm{ml}(31)$.

Previous studies have demonstrated decreased plasma PA levels in patients with hyperthyroidism $(22,27,31$, 34 ), with generally normal or near normal levels in patients with hypothyroidism. The thyroxine-binding capacity of PA, or the level of PA, has been reported to be decreased in patients with a variety of malignant diseases (30), after surgery (32), during pregnancy both pre- and postpartum (31), and in the presence of fever and of a number of acute and chronic illnesses $(22,27)$. Low PA levels, similar to those reported here, have also been observed in patients with cirrhosis (33).

In the present studies, plasma from patients with thyroid disease was examined in order to explore how $\mathrm{RBP}$ levels would relate to altered PA concentrations in these patients. Both RBP and PA levels were significantly lower than normal in hyperthyroid patients. In hypothyroidism, neither the level of PA nor of RBP was significantly different than normal. Moreover, in both hyper- and hypothyroidism the molar ratios of RBP: $\mathrm{PA}$ and of RBP : vitamin A were not significantly different from normal. These findings suggest that abnormalities in thyroid status have similar effects on the metabolism of both RBP and PA, i.e., on the entire vitamin A transport system. The mechanisms responsible for these effects remain to be explored.

The studies on chronic renal disease were undertaken in order to obtain information about the role of the kidneys in the metabolism of RBP. It has been known since the 1940's that patients with severe renal disease often have elevated plasma levels of vitamin A $(15,19,35$, $36)$. In previous reports from our laboratory $(2,3)$ it was pointed out that, in view of the relatively small size of RBP (mol wt 21,000), free, uncomplexed RBP would be filtered fairly readily by the glomerulus. It was suggested that the formation of the RBP-PA complex served to protect $\mathrm{RBP}$ by preventing its glomerular filtration. Considerable information is available about the role of the kidney in the metabolism of low molecular weight serum proteins. The kidneys are, for example, known to play an important role in the metabolism of L-chains (37), Bence Jones proteins (38), growth hormone (39), insulin $(40,41)$, and ribonuclease (42). In a recent study, Mogielnicki, Waldmann, and Strober examined the metabolism of immunoglobulin L-chains, mol wt 24,000, in mice with experimental renal disease (37). These workers concluded that in normal states, small proteins which are filtered with relative ease through the glomeruli are taken up and catabolized in the tubular cells. In tubular proteinuria when the glomerular filtration rate is normal, protein filtration continues unchanged, but tubular uptake and catabolism decrease; more protein hence appears in the urine but there is no change in the over-all protein metabolic rate. In the presence of renal disease with greatly decreased glomerular filtration rate, less protein passes into the tubular lumen, with a resultant decline in the rate of catabolism (and excretion) of the protein. It was pointed out (37) that these latter abnormalities would explain the high serum levels and prolonged survival of certain small proteins in uremia.

Since uncomplexed RBP can be expected to be filtered fairly readily through the glomeruli, whereas neither PA nor the RBP-PA complex would be filtered appreciably, the importance of the kidneys in the metabolism of RBP would depend, to a major extent, on the proportion of RBP present in plasma in the free, uncomplexed state. We have previously reported that the metabolic clearance rate of $\mathrm{RBP}_{-}{ }^{131} \mathrm{I}$ in normal subjects is of the order of 8 liters/day per $\mathrm{m}^{2}$ body surface area (43). It was also estimated that the value of $K_{a}$, the association constant for the formation of a complex between RBP and PA, may be of the order of $10^{8}$ at physiological $\mathrm{pH}$ in vivo (3). If this value were correct, it can be calculated from the normal levels of RBP and $\mathrm{PA}$ and the normal glomerular filtration rate that the renal metabolism of RBP would be relatively minor, accounting for the metabolic clearance (of RBP) of only approximately 0.6 liters of plasma or less per day. If the values of $K_{a}$ were $10^{7}$ or $3 \times 10^{8}$, and if the glomerular membrane were fully permeable to uncomplexed RBP, glomerular filtration and renal metabolism would account for the metabolic clearance of 6 liters and of 17 liters, respectively, of plasma per day and would be of considerable quantitative importance in the overall metabolism of RBP. 
In the group of patients with azotemic renal disease studied, both plasma RBP and vitamin A levels were greatly elevated, while PA levels remained normal. In contrast with the patients with liver and thyroid disease, the molar ratio of RBP:PA was grossly abnormal, in many instances being elevated considerably above 1 . These findings suggest that the kidneys normally play an important role in the metabolism of RBP, and that sufficient RBP normally circulates in the uncomplexed state that its renal metabolism (as a low molecular weight protein) is of considerable quantitative significance. It is hence likely that the normal value of $K_{a}$ under physiological conditions is of the order of $10^{7}$ (or slightly less) rather than of the order of $10^{3}$.

The gel filtration experiments (Figs. 7 and 8) directly demonstrated the presence of considerable amounts of free RBP in plasma from patients with renal disease and with $\mathrm{RBP}: \mathrm{PA}$ ratios greater than 1 . In fact, the relative distribution of $\mathrm{RBP}$ between the RBP-PA complex and free $R B P$ in these samples suggested that the affinity of RBP for PA $\left(K_{a}\right)$ was less than normal in the plasma of these azotemic patients. Addition of PA to one sample demonstrated that the RBP present as free $\mathrm{RBP}$ and in molar excess was capable of forming a complex with PA and was hence structurally relatively intact. It was found that the molar ratio of RBP : vitamin A was abnormal in renal disease, with plasma RBP circulating less saturated with retinol than normal. Moreover, the gel filtration experiments suggested that the affinity of apo-RBP (not containing retinol) for PA was less than that of holo-RBP. These findings are consistent with the hypothesis that under normal conditions the small amount of apo-RBP normally present (1) is preferentially filtered in the glomeruli because of its lesser affinity (compared with holo-RBP) for PA. In renal disease the retention of apo-RBP would accordingly be relatively more prominent than that of holo- $R B P$, accounting for the elevated RBP: vitamin $A$ ratio seen in these patients. A lesser affinity of apo-RBP than holoRBP for PA would provide a mechanism for the selective catabolism of the apoprotein in both normal and abnormal conditions.

\section{ACKNOWLEDGMENTS}

We are grateful to Miss M. Alvir for expert assistance. We thank Dr. L. Kagen for helpful discussions regarding radial gel diffusion, Doctors R. Rivlin and M. Primack for providing plasma samples from patients with thyroid disease, and Dr. D. Gocke for providing some samples from patients with hepatitis and for measuring plasma Australia antigen.

This work was supported by Grants AM-05968 and HE05741 from the National Institutes of Health, U. S. Public Health Service, and by Contract No. DADA 17-70-C-0002 from the Department of the Army.

\section{REFERENCES}

1. Smith, F. R., A. Raz, and D. S. Goodman. 1970. Radioimmunoassay of human plasma retinol-binding protein. J. Clin. Invest. 49: 1754.

2. Kanai, M., A. Raz, and D. S. Goodman. 1968. Retinolbinding protein: the transport protein for vitamin A in human plasma. J. Clin. Invest. 47: 2025.

3. Raz, A., T. Shiratori, and D. S. Goodman. 1970. Studies on the protein-protein and protein-ligand interactions involved in retinol transport in plasma. J. Biol. Chem. 245: 1903.

4. Raz, A., and D. S. Goodman. 1969. The interaction of thyroxine with human plasma prealbumin and with the prealbumin-retinol-binding protein complex. J. Biol. Chem. 244: 3230 .

5. Hawk, P. B., B. L. Oser, and W. H. Summerson. 1954. Practical Physiological Chemistry. Blakiston Company, New York. 13th edition. 545.

6. Goodale, R. H., and F. K. Widmann. 1969. Clinical Interpretation of Laboratory Tests. F. A. Davis Co., Philadelphia. 6th edition. 96.

7. Pileggi, V. J., N. D. Lee, O. J. Golub, and R. J. Henry. 1961. Determination of iodine compounds in serum. I. Serum thyroxine in the presence of some iodine contaminants. J. Clin. Endocrinol. Metab. 21: 1272.

8. Dugan, R. E., N. A. Frigerio, and J. M. Siebert. 1964. Colorimetric determination of vitamin $\mathrm{A}$ and its derivatives with trifluoroacetic acid. Anal. Chem. 36: 114.

9. Roels, O., and S. Mahadevan. 1967. Vitamin A. In The Vitamins; Chemistry, Physiology, Pathology, Methods. P. György and W. N. Pearson, editors. Academic Press, Inc., New York. 2nd edition. 6: 156.

10. Thompson, J. N., P. Erdody, R. Brien, and T. K. Murray. 1970. Phytofluene in human blood and the fluorometric determination of vitamin A. Fed. Proc. 29: 564. (Abstr.)

11. Olivetti Underwood Programma 101, Statistical Analysis Manual. 1969. J. B. Williams, editor. Olivetti Underwood Corp., New York. 68.

12. Snedecor, G. W., and W. G. Cochran. 1967. Statistical Methods. Iowa State University Press, Ames, Iowa. 6th edition. 184.

13. Mainland, D. 1952. Elementary Medical Statistics; the Principles of Quantitative Medicine. W. B. Saunders Company, Philadelphia. 157.

14. Moore, T. 1957. Vitamin A. American Elsevier Publishing Co., Inc., New York. 208.

15. Popper, H., F. Steigmann, K. A. Meyer, and S. S. Zevin. 1943. Relation between hepatic and plasma concentrations of vitamin A in human beings. Arch. Intern. Med. 72: 439.

16. Harris, A. D., and T. Moore. 1947. Vitamin A in infective hepatitis. Brit. Med. J. 1: 553.

17. Patek, A. J., Jr., and C. Haig. 1939. The occurrence of abnormal dark adaptation and its relation to vitamin A metabolism in patients with cirrhosis of the liver. J. Clin. Invest. 18: 609.

18. Ralli, E. P., E. Papper, K. Paley, and E. Bauman. 1941. Vitamin A and carotene content of human liver in normal and in diseased subjects. Arch. Intern. Med. 68: 102 .

19. Popper, H., F. Steigmann, A. Dubin, H. A. Dyniewicz, and F. P. Hesser. 1948. Significance of vitamin A alcohol and ester partitioning under normal and pathologic circumstances. Proc. Soc. Exp. Biol. Med. 68: 676. 
20. Ingbar, S. H. 1963. Observations concerning the binding of thyroid hormones by human serum prealbumin. $J$. Clin. Invest. $42: 143$.

21. Robbins, J., and J. E. Rall. 1960. Proteins associated with the thyroid hormones. Physiol. Rev. 40: 415.

22. Oppenheimer, J. H. 1968. Role of plasma proteins in the binding, distribution and metabolism of the thyroid hormones. N. Engl. J. Med. 278: 1153.

23. Oppenheimer, J. H., M. I. Surks, J. C. Smith, and R. Squef. 1965. Isolation and characterization of human thyroxine-binding prealbumin. J. Biol. Chem. 240: 173.

24. Woeber, K. A., and S. H. Ingbar. 1968. The contribution of thyroxine-binding prealbumin to the binding of thyroxine in human serum, as assessed by immunoadsorption. J. Clin. Invest. 47: 1710.

25. Lutz, J. H., and R. I. Gregerman. 1969. $\mathrm{pH}$ dependence of the binding of thyroxine to prealbumin in human serum. J. Clin. Endocrinol. Metab. 29: 487.

26. Ingbar, S. H., and N. Freinkel. 1960. Regulation of the peripheral metabolism of the thyroid hormones. Recent Progr. Hormone Res. 16: 353.

27. Oppenheimer, J. H., R. Squef, M. I. Surks, and H. Hauer. 1963. Binding of thyroxine by serum proteins evaluated by equilibrium dialysis and electrophoretic techniques. Alterations in non-thyroidal illness. J. Clin. Invest. 42: 1769.

28. Socolow, E. L., K. A. Woeber, R. H. Purdy, M. T. Holloway, and S. H. Ingbar. 1965. Preparation of $\mathrm{I}^{182}$ labeled human serum prealbumin and its metabolism in normal and sick patients. J. Clin. Invest. 44: 1600.

29. Oppenheimer, J. H., M. Martínez, and G. Bernstein. 1966. Determination of the maximal binding capacity and protein concentration of thyroxine-binding prealbumin in human serum. J. Lab. Clin. Med. 67: 500 .

30. Bellabarba, D., M. Inada, N. Varsano-Aharon, and K. Sterling. 1968. Thyroxine transport and turnover in major nonthyroidal illness. J. Clin. Endocrinol. Metab. 28: 1023.

31. Sakurada, T., S. Saito, K. Inagaki, S. Tayama, and T. Torikai. 1968. Concentration and binding capacity of thyroxin-binding prealbumin in pregnancy, hyper- and hypothyroidism. Tohoku J. Exp. Med. 96: 259.

32. Surks, M. I., and J. H. Oppenheimer. 1964. Postoperative changes in the concentration of thyroxine-binding prealbumin and serum free thyroxine. J. Clin. Endocrinol. Metab. 24: 794 .

33. Agostoni, A., C. Vergani, R. Stabilini, and A. Petrella. 1968. Thyroxine-binding prealbumin in alcoholic cirrhosis. Lancet. 1: 926.

34. Vergani, C., R. Stabilini, and A. Agostoni. 1969. Thyroxine-binding prealbumin in thyrotoxicosis and hypothyroidism. Clin. Chem. 15: 216.

35. Popper, H., F. Steigmann, and H. A. Dyniewicz. 1945. Plasma vitamin A level in renal diseases. Amer. J. Clin. Pathol. 15: 272.

36. Kagan, B. M., E. M. Thomas, D. A. Jordan, and A. F. Abt. 1950. Serum vitamin A and total plasma lipid concentrations as influenced by the oral administration of vitamin A to children with the nephrotic syndrome. J. Clin. Invest. 29: 141

37. Mogielnicki, R. P., T. A. Waldmann, and W. Strober. 1971. The renal handling of low molecular weight proteins. I. L-chain metabolism in experimental renal disease. J. Clin. Invest. 50: 901.

38. Wochner, R. D., W. Strober, and T. A. Waldmann. 1967. The role of the kidney in the catabolism of Bence Jones proteins and immunoglobulin fragments. J. Exp. Med. 126: 207

39. Samaan, N. A., and R. M. Freeman. 19\%0. Growth hormone levels in severe renal failure. Metab. Clin. Exp. 19: 102 .

40. Chamberlain, M. J., and L. Stimmler. 1967. The renal handling of insulin. J. Clin. Invest. 46: 911.

41. Rabkin, R., N. M. Simon, S. Steiner, and J. A. Colwell. 1970. Effect of renal disease on renal uptake and excretion of insulin in man. N. Engl. J. Med. 282: 182.

42. Houck, J. C., and L. B. Berman. 1958. Serum ribonuclease activity. J. Appl. Physiol. 12: 473.

43. Smith, F. R., and D. S. Goodman. 1970. Metabolism of plasma retinol-binding protein in man. J. Clin. Invest. 49: 90a. (Abstr.) 